\title{
THE USE OF ECONOMETRIC MODELS IN THE STUDY OF DEMOGRAPHIC POLICY MEASURES (BASED ON THE EXAMPLE OF FERTILITY STIMULATION IN RUSSIA)
}

\author{
Oksana Shubat \\ Anna Bagirova \\ Ural Federal University \\ 620002, Ekaterinburg, Russia \\ Email: o.m.shubat@urfu.ru \\ Email: a.p.bagirova@urfu.ru
}

\section{KEYWORDS}

Econometric models, time series analysis, demographic policy, total fertility rate, maternity capital

\begin{abstract}
Russia is experiencing steady population decline. One of the reasons for this is low fertility. The other major problem is insufficient housing availability. In today's political discussion, these two problems are often presented as interconnected. The aim of our research is to analyse the relationship between fertility dynamics and provision of housing in Russia in order to subsequently assess the effectiveness of the most expensive measure for stimulating fertility in the state's history - the so-called "maternity capital". We estimated regression models for the time series of fertility rates and the availability of housing. To assess the strength of relationship between the time series, we analysed correlation between regressions' residuals in two models.A retrospective analysis of the time series showed no correlation between the two in a historical context. Throughout the time that the maternity capital was in place the correlation analysis also revealed no relationship between them. Our analysis showed that these variables were not significantly correlated either in urban or rural Russian areas. We can conclude that the introduction of maternity capital in Russia was not underpinned by profound statistical and demographic analysis. Our results also give reason to question the effectiveness of maternity capital.
\end{abstract}

\section{INTRODUCTION}

Like most European countries, Russia is experiencing steady population decline. One of the reasons for this is low fertility. In 2015 , the total fertility rate (TFR) was 1.78 , which is $15.2 \%$ below the replacement fertility rate (Total Fertility Rate 2016). This is of concern to country's leadership, which is interested in economic growth and a strengthening of Russia's demographic potential.

The other major issue in our country, which has been around since Soviet times, is insufficient housing availability. For example, the average number of rooms shared per person in a dwelling in Russia is almost half that in Germany and France (Housing 2016).. In early 1986, future USSR president Mikhail Gorbachev promised that by the year 2000, every family would live in their own flat or house. The USSR adopted a state programme called "Housing-2000". However, the collapse of the Soviet Union derailed the implementation of the program. People only received the opportunity to become homeowners in 1991 (Federal law 1541-I 1991); until this time, flats were mostly distributed free of charge through a queue-based system, which could last decades.

In today's political discussion, these two problems are often presented as interconnected. At the same time, Russian demographers see insufficient housing as just one of many causes of low fertility (Rotova 2012). According to the theory put forward by V. Borisov, V. Arkhangelsky, A. Antonov et al., there are two sets of factors behind low birth rates: socio-psychological (in other words, a low desire for children) and socioeconomic (or poor conditions for actualising the desire for children) (Arkhangelsky 2012). The first group includes factors like the desire to have a particular number of children, widespread social norms regarding the number of children and so on. The second set of factors includes income levels, living conditions, accessibility of kindergartens and the like. Notably, the influence of these groups of factors is interconnected and one cannot talk about fertility being determined solely by economic conditions without accounting for the desire for children. As such, an improvement in the population's economic conditions in and of itself will not lead to a growth in fertility.

Existing state measures for supporting fertility in Russia entail every type of assistance for families spelled out by O. Thevenon and A. Gauthier: assistance to pregnant women; assistance at childbirth; assistance aimed at providing parents with the opportunity to combine childcare and paid employment; payments to parents who look after children (Thevenon and Gauthier 2011). Moreover, in 2007 Russia introduced an unprecedented measure for stimulating fertility - the socalled "maternity capital". This entails a lump-sum payment after the birth of the second (or third and so on) child and can only be received once. The amount (around 7,750 EUR in 2017) can be spent on housing betterment, children's education or on the mother's 
future pension. The most popular way to spend this payment is to improve living conditions, with some $95 \%$ of recipients spending the money on housing (Maternity capital in Krasnoyarsk 2016; Statistical data on the expenditure of maternity capital. 2016). Notably, there is great variability across Russia as regards overall standards of living, including the per square metre cost of housing. Moreover, urban housing is always more expensive than rural residences. Yet the maternity capital amount is in no way modified on the basis of where the mother and child live, and is the same across the country.

The impact of demographic policy measures on overall fertility and its individual determinants has been the subject of extensive research around the world. Balbo, Billari and Mills's work presents a wide spectrum of topical results, where all fertility determinants are grouped into three levels: micro (determinants at the individual and/or couple level); meso (social relationships and social networks) and macro (cultural and institutional settings) (Balbo, Billari and Mills 2013). In Russia, sociologists chiefly study the desire for children among different categories of women, whereas research into socio-economic conditions for actualising these desires is far less prevalent (Sinitca 2012). At the same time, as Sinitsa notes, "Russian research contains extensive recommendations as regards state policy, whereas international studies mostly describe existing processes" (Sinitca 2012: 106).

Undoubtedly, the introduction of a rather expensive mechanism for stimulating fertility should have been preceded by a profound analysis of the demographic and socio-economic situation across different Russian regions. As such, the aim of our research is to analyse the relationship between fertility dynamics and provision of housing in Russia in order to subsequently assess the effectiveness of the most expensive measure for stimulating fertility in the state's history.

We note that maternity capital has been used in Russia as a demographic policy tool for 10 years. The country's leadership regularly praises its effectiveness, but to date, there has been no fundamental scientific research to support these claims.

\section{DATA AND METHODS}

1. In the course of our research, we studied the time series for the following indicators:

- We used the average number of square metres of housing per resident to describe the level of housing availability. This is the most accessible and commonly occurring indicator on people's standards of living in Russian statistics. This data is publicly available from 1980 (Living standards data 2016).

- We used Total Fertility Rate to describe fertility, as it can provide an integrated representation of fertility intensity across different age groups. Russian statistics data for this is available over a much more extended period of time. However, for our analysis, we applied a comparable period and only used data from 1980 onwards (Total Fertility Rate data 2016).

2. To explore the correlation between the time series, we tried to to exclude spurious correlation. We estimated regression models for the stated time series and used ordinary least squares as the method for estimating the parameters of the models. In certain cases, we found autocorrelation of the residuals $(\operatorname{AR}(1))$. Since we excluded an incorrect model specification, we removed autocorrelation by estimating such models on the basis of generalized least squares, Cochrane-Orcutt iterative procedure and Prais-Winsten correction. To assess the strength of relationship between the time series, we used Pearson and Spearman correlation. We analysed correlation between regression residuals in two models.

3. To test the hypothesis about the possible influence of maternity capital on growing fertility, we estimated models and tested the relationship between the studied variables separately for two periods of time: 1) for the entire period available for analysis; 2) for the period since the measure was introduced (i.e. between 2007 and now).

4. To test the hypothesis about possibly greater influence of maternity capital on fertility outside large cities, we estimated the correlation between the studied variables separately in urban and rural areas. We considered this an important aspect of the study, because we supposed that the effectiveness of this fertility incentive measure should be greater in rural areas - in parts of the country where housing costs less.

\section{RESULTS}

1. A retrospective analysis of the time series characterizing fertility levels in the country and the provision of housing to the population showed no correlation between the two in a historical context. Thus, since the $1980 \mathrm{~s}$, the average number of square metres of housing per person in Russia steadily grew (Figure 1).

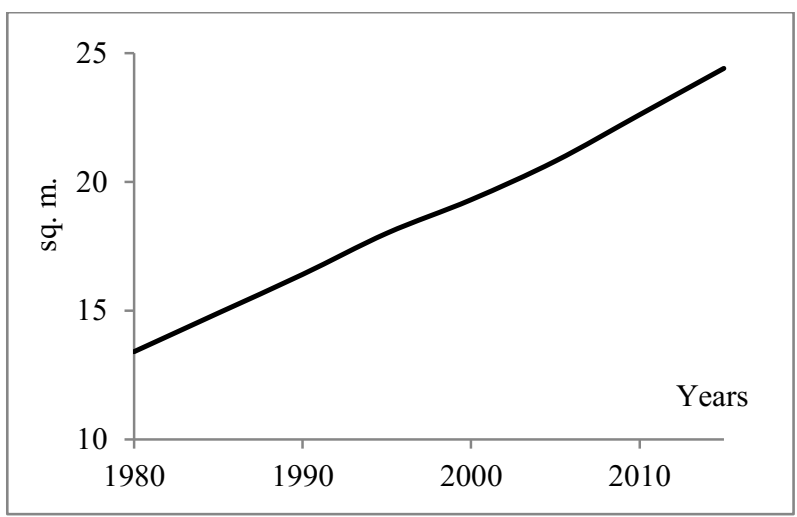

Figure 1: Average Number of Square Metres of Housing per Person in Russia (Living standards data 2016) 
Yet over the long run, TFR moved in different directions. Thus, between the mid-1980s and the end of the century, this indicator was declining, only moving into a growth phase in 2000. Since then, TFR grew consistently (except 2005, when fertility fell) - a trend that is observed to date (Figure 2).

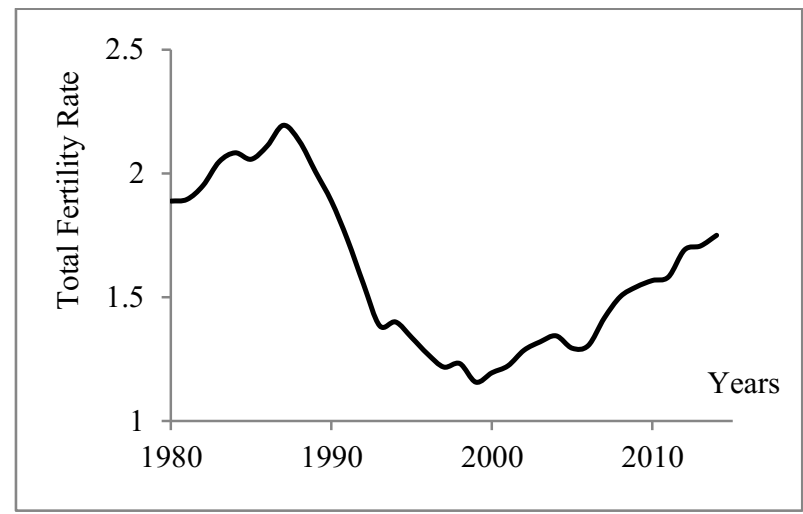

Figure 2: Total Fertility Rate in Russia (Total Fertility Rate data 2016)

Since the two trends became unidirectional in 2000, the subsequent modelling of the possible relationship between the two was done for this period.

2. Modelling trend in the availability of housing between 2000 and 2015 showed that this time series is well approximated by a linear trend. Year-on-year, housing availability grew by an average of 0.34 sq.m. per person in the country (tables 1-3).

Table 1: Model Summary

(dependent variable: model 1 - average number of sq.m. of housing per person; model 2 - TFR)

\begin{tabular}{|c|c|c|c|c|}
\hline 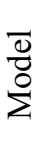 & 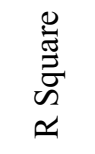 & 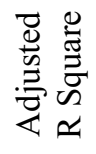 & 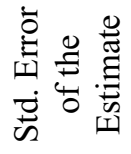 & 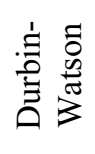 \\
\hline 1 & 0.995 & 0.995 & 0.1190 & 1.502 \\
\hline 2 & 0.885 & 0.877 & 0.0358 & 1.565 \\
\hline
\end{tabular}

Table 2: ANOVA

(dependent variable: model 1 - average number of sq.m. of housing per person; model 2 - TFR)

\begin{tabular}{|c|c|c|c|c|c|c|}
\hline & $\begin{array}{l}\frac{0}{0} \\
\sum\end{array}$ & 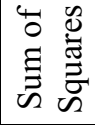 & 4 & 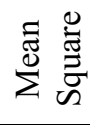 & I & $\frac{000}{\dot{\infty}}$ \\
\hline & Regression & 39.41 & 1 & 39.41 & 2781.95 & 0.000 \\
\hline 1 & Residual & 0.19 & 14 & 0.01 & & \\
\hline & Total & 39.60 & 15 & & & \\
\hline & Regression & 0.14 & 1 & 0.14 & 107.58 & 0.000 \\
\hline 2 & Residual & 0.02 & 14 & 0.00 & & \\
\hline & Total & 0.15 & 15 & & & \\
\hline
\end{tabular}

Table 3: Coefficients

(dependent variable: model 1 - average number of sq.m. of housing per person; model 2 - TFR)

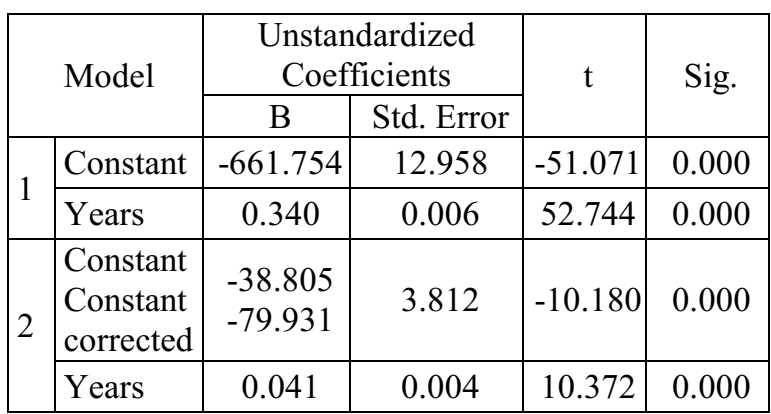

Upon modelling trend in the fertility between 2000 and 2015, we identified an autocorrelation of residuals in the initial model. An estimation on the basis of GLS, Cochrane-Orcutt iterative procedure and Prais-Winsten correction enabled us to identify an increasing linear trend in TFR dynamics with an average annual increase of 0.041 (tables 1-3).

3. Correlation analysis of regressions' residuals showed that fertility and housing availability in the examined period were not correlated (table 4).

Table 4: Correlations between TFR and housing availability (from 2000 to 2015)

\begin{tabular}{|l|l|}
\hline \multicolumn{1}{|c|}{ Indicator } & Value \\
\hline Pearson Correlation & 0.366 \\
\hline Sig. (2-tailed) Pearson Correlation & 0.164 \\
\hline Spearman's rho & 0.279 \\
\hline Sig. (2-tailed) Spearman's rho & 0.295 \\
\hline
\end{tabular}

4. Throughout the time that the maternity capital fertility stimulation programme was in place (2007 to 2015), the studied indicators grew. Yet the availability of housing in this period grew by $14 \%$, whereas birth rates grew much more - by $25.5 \%$.

5. Modelling the trends over the stated period and examining the correlations revealed no relationship between the availability of housing and fertility rates since the introduction of the maternity capital programme (table 5).

Table 5: Correlations between TFR and housing availability (from 2007 to 2015 )

\begin{tabular}{|l|c|}
\hline \multicolumn{1}{|c|}{ Indicator } & Value \\
\hline Pearson Correlation & -0.014 \\
\hline Sig. (2-tailed) Pearson Correlation & 0.972 \\
\hline Spearman's rho & 0.017 \\
\hline Sig. (2-tailed) Spearman's rho & 0.966 \\
\hline
\end{tabular}

An analysis with account of a possible lag in changes to fertility in response to improved housing conditions (with a delay of 1-2 years) did not reveal any 
connection between the evaluated variables either. Analogous analysis with account of a possible lag between improved housing conditions in response to greater fertility (as envisaged by the maternity capital programme) also did not reveal any correlation.

6. An analysis of the dynamics of the studied variables by territory showed that throughout the time that the maternity capital programme has been operating, rural indicators have been higher than urban ones. Thus, housing availability in rural areas each year was on average $7.6 \%$ greater than in cities; TFR in rural areas was on average $39.6 \%$ higher each year than in urban ones.

On the whole, between 2007 and 2015, housing availability grew both in cities and in non-urban areas. The difference in growth proved insignificant $(13.7 \%$ and $14 \%$ ). Yet the difference in fertility growth was marked $(29.7 \%$ in cities and $17.4 \%$ in rural areas).

7. Modelling trends separately for cities and rural areas showed that the evaluated time series throughout the time of the maternity capital programme is well approximated by linear trends. Correlation analysis of regressions'residuals showed that birth rates and housing availability in the examined period were not significantly correlated either in urban or rural areas (table 6). Correlation analysis with lag effects also did not uncover any relationship.

Table 6: Correlations between TFR and housing availability by territory (from 2000 to 2015 )

\begin{tabular}{|l|c|c|}
\hline \multicolumn{1}{|c|}{ Indicator } & $\begin{array}{c}\text { Value for } \\
\text { urban areas }\end{array}$ & $\begin{array}{c}\text { Value for } \\
\text { rural areas }\end{array}$ \\
\hline Pearson Correlation & 0.500 & -0.069 \\
\hline $\begin{array}{l}\text { Sig. (2-tailed) } \\
\text { Pearson Correlation }\end{array}$ & 0,170 & 0.859 \\
\hline Spearman's rho & 0.383 & -0.083 \\
\hline $\begin{array}{l}\text { Sig. (2-tailed) } \\
\text { Spearman's rho }\end{array}$ & 0.308 & 0.831 \\
\hline
\end{tabular}

\section{DISCUSSION}

The lack of correlation between the dynamics of birth rates and housing availability in Russia gives reason to question the effectiveness of maternity capital, the most expensive state-funded fertility stimulation programme in the country's history. Our results give rise to a number of discussion points.

First of all, we believe there are two main reasons for the registered growth of TFR in Russia in recent years:

1. The introduction of maternity capital could have had a certain effect on the total number of births per woman and the timing of childbearing. Thus, women who had unstable reproductive plans in 2007 may have been prompted to have a child after this programme was implemented (the so-called postponement of childbearing effect). Moreover, one could suppose that some people (particularly rural dwellers) misunderstood information about the rollout of maternity capital, believing that they could spend the money as soon as their second child was born, in whatever way they saw fit;

2 A certain positive effect could be the result of the relatively successful development of the Russian economy between 2007 and 2015. In this period, per capita GDP grew 1.45 times, according to IMF data (Gross domestic product 2016). Despite the observation made by, for example, Sobotka et al, that the relationship between TFR and GDP is contradictory (Sobotka, Skirbekk and Philipov 2011), there is research that clearly registers a positive correlation between these indicators. Thus, Martin identified this connection for Australia (Martin 2004), Santow and Brachner - for Sweden (Santow and Bracher 2001), and so on.

In our view, it is important to note that the growth in TFR happened against a background of a negative influence of structural factors on total births in Russia. Indeed, in this period, there was a significant decline in the proportion of women of fertile age in the total female population. Thus in 2002 it was $43.6 \%$, compared to $39.4 \%$ in 2015 . The number of women of this age declined by 2.9 million people during this period.

We would also note that despite the growth in TFR, its value during the studied period was below the replacement fertility rate (2.1). Moreover, the total effectiveness of maternity capital measure would have to lead TFR to increase by at least 1.0 (if one is to imagine that women of fertile age would, upon learning of this unprecedented support, choose to use it immediately). However, official Russian statistics for 2007-2008 registered a growth in TFR of just 0.086 . This shows that in 2008 , only every 12 th woman gave birth to one child more than in the previous year (moreover, it is unclear whether that decision was the result of the introduction of maternity capital).

If one is to accept the hypothesis that maternity capital and the potential improvement in living conditions it promises influences the average number of births for a Russian woman, its impact should be greater for rural areas, where living standards and living costs are lower. Statistical data disprove this hypothesis. When it comes both absolute and relative values, the growth in TFR was greater for women from cities.

It is also clear that before the introduction of such a costly fertility stimulation programme, no retrospective analysis of relationships between fertility levels and housing availability was carried out. Our data show that there is no positive correlation between these indicators. This is supported by research by other Russian scientists. For example, Maleva and Sinyavskaya estimated the probability of childbirth depending on various socio-economic indicators between 2001 and 2004 (Maleva and Sinyavskaya 2007). They registered that for women who already have children, the decision to have another child was in no way connected to living conditions. These researchers note that "ceteris paribus, housing availability statistically significantly increases 
the likelihood of childbearing in the model of all completed births, and with respect to the model for first children most of all. However, it proves insignificant for the birth of the second and subsequent child" (Maleva and Sinyavskaya 2007: 183). As such, it can be asserted that from the outset, maternity capital was not able to influence the very category of women at whom it was aimed (women who have one child and are potentially ready to have another).

Moreover, we consider the content of this programme to be rather ill-thought through for reasons that include:

1) strong variability across Russia as regards standard of living with the same maternity capital amount for different regions. This leads to varying perceptions about the impact of this measure for different groups of the population. As such, the very mechanism was initially aimed at stimulating fertility in the most economically laggard parts of Russia;

2) such significant amounts (in 2016 alone, Russia spent RUB 304.3 billion (Federal law 364-FZ 2015) or EUR 4.77 billion on maternity capital) are allocated solely for the birth of a child, rather than for supporting his subsequent upbringing and development. Thus, we believe that people are presented with a certain "message" that the state cares most about the quantity and not the 'quality' of children. We note that there are many international examples of a more balanced demographic policy. For example, in France, child benefits are paid from the second child onwards, until the child turns 20 and the amount grows with the number of children and their age (Köppen 2006).

\section{CONCLUSIONS}

A study of cause-and-effect relationships between variables presented as time series is one of the difficulties of econometric modelling. This could explain the deficit of Russian demographic research that uses such instruments. At the same time, econometric modelling has high heuristic potential and could become the basis for developing more effective demographic policy measures. Firstly, such modelling enables justifying the expedience of a particular demographic policy measure (by studying the potential relationship between variables that are expected to be affected by its introduction). Secondly, the use of econometric methods allows adjusting the substance of the developed measures.

On the basis of the results we obtained, we can suppose that the introduction of maternity capital in Russia as a state measure for stimulating fertility was not underpinned by profound statistical and demographic analysis. Thus, we believe that there were insufficient grounds to tie the introduced demographic measures solely with changes to the provision of housing. Moreover, the differentiation of Russian regions was not taken into consideration, which fully negated the possible impact of introducing the maternity capital programme. For example, our earlier research showed that countries with a large number of constituent parts with high variance in their development require a demographic policy that is differentiated by type of region (Shubat et al 2016). Such development of targeted measures for different types of regions would improve the effectiveness of Russia's overall demographic policy. On the whole we note that such a strong emphasis on one economic measure for stimulating fertility without creating conditions to drive greater desire for children among the Russian population could not, from the outset, lead to higher fertility - the goal of demographic policy in contemporary Russia.

\section{ACKNOWLEDGMENTS}

The work was supported by Act 211 Government of the Russian Federation, contract № 02.A03.21.0006. The project was also sponsored by the Graduate School of Economics and Management of Ural Federal University.

\section{REFERENCES}

Arkhangelsky, V.N. 2012. Methodological issues in research into determinants of demographic processes. In: Zvereva, N.V. and Arkhangelsky, V.N. (eds.) Determinants of demographic processes: compendium. Moscow: Maks Press.

Balbo, N., Billari, F. C. and Mills, M. 2013. "Fertility in Advanced Societies: A Review of Research". European Journal of Population / Revue Européenne De Démographie, Vol 29, Issue 1, 1-38.

Federal law 1541-I from 04.07.1991 "On the privatization of housing in the Russian Federation"

Federal law 364-FZ from 14.12.2015 "On the budget of the Russian Federation Pension Fund for 2016"

Gross domestic product per capita, current prices. 2016. International Monetary Fund. URL: http://www.imf.org/external/pubs/ft/weo/2016/02/w eodata/weorept.aspx?pr.x=64\&pr.y=11\&sy=1997\&e $\mathrm{y}=2021 \&$ scsm $=1 \&$ ssd $=1 \&$ sort $=$ country \&ds $=. \& b r=1$ $\& c=922 \& s=$ NGDPDPC $\&$ grp $=0 \& a=$ (access date 21.01.2017)

Housing. OECD Better Life Index. 2016. URL: http:/www.oecdbetterlifeindex.org/topics/housing/ (access date 21.01.2017)

Köppen, K. 2006. "Second Births in Western Germany and France". Demographic Research, Vol 14, 295330. Retrieved January 21, 2017, from http://www.demographicresearch.org/volumes/vol14/14/

Living standards data. 2016. The Federal State Statistics Service. Rosstat, Moscow. URL: http://www.gks.ru/wps/wcm/connect/rosstat_main/r osstat/ru/statistics/population/level/ (access date 21.01.2017)

Maleva, T. and Sinyavskaya, O. 2007. Socio-economic factors of fertility in Russia: Empirical measurement and social policy challenges. In T. Maleva \& O. Sinyavskaya (Eds.), Parents and Children, Men and Women in Family and Society. URL: 
http://www.socpol.ru/publications/pdf/PiDMiG1_en d.indd.pdf (access date 21.01.2017)

Martin, J. 2004. "The Ultimate Vote of Confidence': Fertility Rates and Economic Conditions in Australia, 1976-2000”. Australian Social Policy 2002-2003. Canberra: Commonwealth of Australia.

Maternity capital in Krasnoyarsk and Krasnoyarsk Territory. 2016. URL: http://pro-materinskiykapital.ru/regionalniy/v-krasnoyarske-ikrasnoyarskom-krae/ (access date 21.01.2017)

Rotova, R. S. 2012. On the socio-economic determinants of fertility. In: Zvereva, N.V. and Arkhangelsky, V.N. (eds.) Determinants of demographic processes: compendium. Moscow: Maks Press.

Santow, G. and Bracher, M. 2001. "Deferment of the first birth and fluctuating Fertility in Sweden". European Journal of Population, Vol 17, Issue 4, 343-363.

Shubat, O., Bagirova, A., Abilova, M. and Ivlev, A. 2016. "The Use of Cluster Analysis for Demographic Policy Development: Evidence From Russia". ECMS-2016: 30th European Conference on Modelling and Simulation, 159-165.

Sinitca, A. L. 2012. Caring for pre-school children as a factor of reproductive behaviour: theoretical approaches. In: Zvereva, N.V. and Arkhangelsky, V.N. (eds.) Determinants of demographic processes: compendium. Moscow: Maks Press.

Sobotka, T., Skirbekk, V. and Philipov, D. 2011. "Economic Recession and Fertility in the Developed World". Population and Development Review, Vol 37, Issue 2, 267-306.

Statistical data on the expenditure of maternity capital in Moscow and Moscow Region. 2016. The Pension Fund of the Russian Federation. URL: http://www.pfrf.ru/branches/moscow/news/ 2015/05 /25/92288 (access date 21.01.2017)

Thevenon, O. and Gauthier, A.H. 2011. "Family Policies in Developed Countries: a "FertilityBooster' with Side-Effects". Community, Work and Family, Vol 14, Issue 2, 197-216.

Total Fertility Rate data. Single inter-departmental information and statistical system (SIDIS). 2016. Rosstat, Moscow. URL: https://fedstat.ru/indicator/55407 (access date 21.01.2017)

\section{AUTHOR BIOGRAPHIES}

OKSANA SHUBAT is an Associate Professor of Economics at Ural Federal University (Russia). She has received her $\mathrm{PhD}$ in Accounting and Statistics in 2009. Her research interests include demographic processes, demographic dynamics and its impact on human resources development and the development of human capital (especially at the household-level). Her email address is: o.m.shubat@urfu.ru and her Web-page can be found at http://urfu.ru/ru/about/personalpages/O.M.Shubat/

ANNA BAGIROVA is a professor of economics and sociology at Ural Federal University (Russia). Her research interests include demographical processes and their determinants. She also explores issues of labour economics and sociology of labour. She is a doctoral supervisor and a member of International Sociological Association. Her email address is: a.p.bagirova@urfu.ru and her Web-page can be found at http://urfu.ru/ru/about/personal-pages/a.p.bagirova/ 